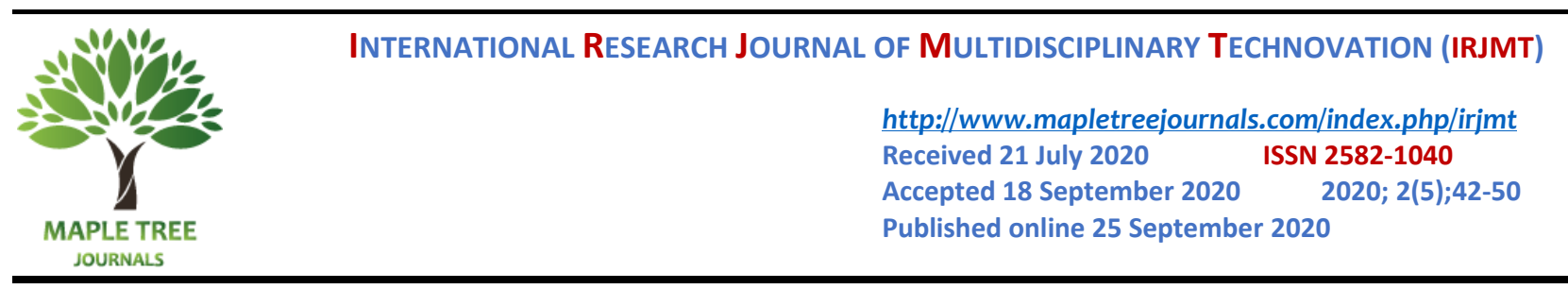

\title{
Alumni Info-Com Management with Distinct Classification of Data
}

\author{
R. Sasikumar ${ }^{1,}{ }^{*}$, B. Haritha ${ }^{1}$, T. Borshiya Vincy ${ }^{1}$, M. Kamali ${ }^{1}$ \\ ${ }^{1}$ Department of Computer Science and Engineering, K. Ramakrishnan College of Engineering, Tiruchirappalli, Tamil \\ Nadu, India. \\ *Corresponding author E-Mail ID: sasi1986@gmail.com
}

DOI: https://doi.org/10.34256/irjmt2057

\begin{abstract}
The Alumni Info-Com Management System is able to manage alumni data of a college and provide easy access to the same. Alumni of college stay in touch with their immediate friends and it is hard to stay connected with college mates. Contact between alumni develops business connections and to gain insight in a new field. Current students will be initially given a student login id. Access to the system can help them to seek help in their projects or for placements. This single system can satisfy almost every requirement of the alumni. Usually, alumni associations are organized in colleges, but may also be organized in a place where the alumni can meet each other. Despite the fact that there are many existing systems in colleges to maintain the alumni information, they are manual and more time consuming to current students to reach out their alumni and maintaining the privacy of the alumni. To overcome these issues, we proposed a web application which allows alumni to update their information and students can connect with them and can view the filtered events posted by alumni and admin through support vector machine algorithm.
\end{abstract}

Keywords: Alumni Information Management, Classification, Support Vector Machine, Guide Juniors.

\section{Introduction}

Data mining is a process of extracting knowledge or patterns from large dataset in our databases. There are various techniques that have been used to discover such kind of knowledge, most of them resulting from machine learning and information. Data mining is an incorporative subfield of computer science and statistics with an aim to draw out information (with intelligent methods) from a data set and transmute the information into a digestible structure for further use. The major part of these methods concentrates on the disclosure of accurate knowledge. This knowledge is useful only if it removes unwanted information to the end user. Data mining techniques are resulted to reduce the consumption of time.

The alumni involvement is the most important part of an educational institute or a foundation. A portion of esteem of a college rests on its Alma Mater. After the students completing their education, they begin their voyage in the corporate world. Reuniting with their friends in the college has been a very significant part of their memory. Alumni web portals are not only for bridging a path between alumni with their friends and college. It is also necessary for lending the helping hand to the currently studying students to improve their knowledge. In this modern era, students should equip themselves with lots of knowledge. Students should connect with their alumni to update themselves with recent trends and explore the career opportunities. These exploring career opportunities are also for the alumni. Because some may not be employed or some may want to switch their career. 
Various kinds of events will be organized by the college such as conferences, workshops, competitions, value added trainings and placement drives. Through this application, alumni can know information about all these events in the college. The students can pass on their query or their views or experiences on to portal regarding certain internship opportunities and events are allocated. In the past, the admin and Alumni can only update the database when they are in the college. This problem has been overcome in our proposed system that users can update the details from anywhere in this world. Our web application implements a feature that allows alumni and students to restrict their views of posts in the forum using support vector machine algorithm It has added extra features to provide more privacy to alumni information. The system completed in two steps. The initial step is to collect data from current final year students before the end of term. The second step of development will extend the functionality of the system to allow alumni to register by verifying with the details collected in the first step.

\section{Related Works}

Gabriel ResendeGonc [1] et al. In this project they study an undergraduate program which prepare its students for the major needs of the labor market. The main ways to identify what are the demands to be met is creating a method to manage information of its alumni. Overall, by using a few alumni pages as an initial set of sample data, the proposed method was capable of gathering information concerning a number of alumni twice as bigger than adopted conventional method.

Silvia Quarteroni [2] et al. Proposes Interactive question answering (QA) systems, where a dialogue interface enables follow-up and clarification questions. This is for open-domain QA system, ensuring that chat bots can be effective in supporting interactive QA.

Harvard Alumni Association[3] Homepage of this portal shows the features like login menu which allows alumni to login easily, make gift for various events like birthdays or anything else, way to connect for between the junior and the alumni. It also provides features such as, lecture details, news, events and notice. It provides the opportunity for the alumni to donate to the institution. It also has unique feature of embedded video on homepage

IIT Kanpur [4] IIT Kanpur has lectures details with schedule, gallery and lists the users integrated with this portal. Also gives the Donor Initiative Chance. Indian Institute of Technology, Kanpur displays events and information and also there is a unique feature of women alumni convention.

Princeton University Alumni Association [5] Through this portal the junior student can get the solution or the advice for their difficulties, gallery present on the home page. This portal provides the donor initiative in terms of sponsorship. It provides a unique feature that alumni and current students are classified on the basis of regions so that the alumni who belongs to the same region will get listed together.

ITMB Alumni Portal [6]: The homepage of this portal shows the search menu for finding the alumni or student who is integrated with the portal. It has the similar features like all portals we discussed earlier (Harvard Alumni Portal, IIT Kanpur, Princeton University).

Hindustan Institute of Technology and science [7] this portal has alumni, student, admin and faculty members as users. It provides various features such as plan and registers events, advanced search options, featured alumni scrolls etc. But has the drawback of non-members can also access the alumni page and see the news and events.

Subashini [8] et al. the proposed system is a web-based application which can be used by alumni and students with the help of admin. Alumni will be able to organize get-together and find out about job opportunities using this system by updating their profile. 
Erlin [9] et al. this paper presents a technique for text messages classification of collaborative learning skills in online discussion. It proposes support vector machine approach to code the message, which gives the good classification on eight categories of collaborative learning skill.

Takashi Onoda [10] et al. Applied active learning techniques based on Support Vector Machine for assessing successive batches, which is called relevance feedback. The proposed method has been very helpful for document retrieval with relevance feedback evidently. In this paper, they acquire several representations of the Vector Space Model and several selecting rules of displayed documents at all iterations.

Jannieca Camba [11] et al. A number of undergraduate students drop out of the campus or shift out from one program to another, influencing the Philippine university's productivity and lavishing its resources. This study presents valuable information surrounding attrition, estimate the factors affecting it, and develop a prediction model for the weakening of the whole campus using support vector machine algorithm.

Yulei Pang [12] et al. Proposed predicting students' graduation outcomes through support vector machines. In this paper, a group of support vector machines-based model for predicting students' graduation is proposed. Advanced machine learning models improve the effectiveness.

Sasiporn Tongman [13] et al. Classifies Positive or Negative Text Using Features Based on Opinion Words and Term Frequency - Inverse Document Frequency. In this paper, a twofeature vector representing positive and negative moods in each text was prepared and then combined with term frequency - inverse document frequency (TF-IDF) features. kNN and SVM classifiers were comparatively raised by this set and the best accuracy result is produced by SVM classifiers.

Ying Zhao [14] et al. Proposed a method for Delivering Categorized News Items Using RSS Feeds and Web Services. A prototype was implemented using Rapidminer 4.3 as a data mining tool and SVM as a classification algorithm for managing RSS feeds from different news websites. The prototype allows the user to get a particular type of news without subscribing to websites and/or being flooded by unnecessary information, which saves time and effort.

PENG CHEN [15] et al. Proposed Margin Maximization Model of Text Classification Based on Support Vector Machines. Based on the margin maximization principle in the statistical machine learning theory, they propose FSM-ADM model for text categorization, which separates the set of features using weighted odds ratio.

Takashi Onoda [16] et al. Proposed Support Vector Machines based Active Learning for the Relevance Feedback Document Retrieval. In this paper, as application of SVM an interactive document retrieval using the significant selection rule is proposed, which can select the correct documents for the retrieval system and the user.

BO LIU [17] et al. Applied Support Vector Machine for CRM Problem. This paper applies the SVMs to solve the practical CRM problem in a company. Data mining in the CRM aims at learning obtainable knowledge from the customer relationship by machine learning or statistical method.

Manus Ross [18] et al. Proposed a method Using Support Vector Machines to Classify Student Attentiveness for the Development of Personalized Learning Systems. This research applies K-means and SVM machine learning algorithms to automatically classify students as attentive or inattentive using data from a consumer RGB-D sensor. 


\section{Existing System}

The present or existing systems are both manual and computerized. The conventional process is to store alumni and current students' details in ledgers. This will be maintained by each department. So, there is no centralized database. It requires the college to collate all the details of the alumni and maintain it. As it is all about maintaining ledgers, it will consume more space. Another method of computerized is to store the students' information in the excel sheets. It is also same as of manual process except that details entered in ledgers are replaced by excel sheets which will be maintained in the computer without consuming external space in college. It makes advantage of accessing the information at any time. Searching and accessing a particular student record will be somewhat easier in excel sheets than manual one.

Developing from these and all now some colleges maintain a web portal which maintains alumni information. In addition to that it bridges a path a between alumni and currently studying students by providing a forum between them. These portals allow the admin only to post events related to their colleges and other colleges. These forums are public and any members of this portal can see [7].

\section{Disadvantages}

- The conventional method leads to more time and space consuming.

- Tedious process to collect and keep updating the alumni details.

- Difficult to maintain the historical data.

- Difficult to search a particular record

- The excel sheets are not centralized.

- Web portals have lack of privacy.

- Many unrelated information

\section{Proposed System}

The proposed Alumni Info-Com Management with Distinct Classification of Data is discussed in with a system architecture Figure.1. The role of each participant is listed as follows.

- Admin - The admin is a person who manages the whole system. Once alumni is registered, admin should activate their account after verification. Admin can also post events related to placements, workshops, conferences etc. of both our college and other colleges. They can send important messages to both alumni and current students.

- Support vector machine classification algorithm - svm algorithm classifies the view of both placement and other events' posts to the alumni and current students based on their department given during registration

- Alumni - Alumni student is the one who is passed out from the college. After registration by filling some details of them own, alumni can make use of the available features. Employed alumni can post events related to placement, internships etc in their companies or which they came to know. Non-employed alumni can share their skills and knowledge with other alumni and current students. They can also view the events posted by others, related to their department which are filtered by support vector machine algorithm. They can search their friends and can have a healthy chat between them. 
- Current student - Current student is the student who is currently studying in the college. After registration, they can search their alumni on the basis of name, batch or department. They can see certain details of alumni. They can chat with them to clear their doubts regarding education. They can view the placements and other events' posts. Support vector machine algorithm filters the events to that student according to their department.

\section{SYSTEM ARCHITECTURE}

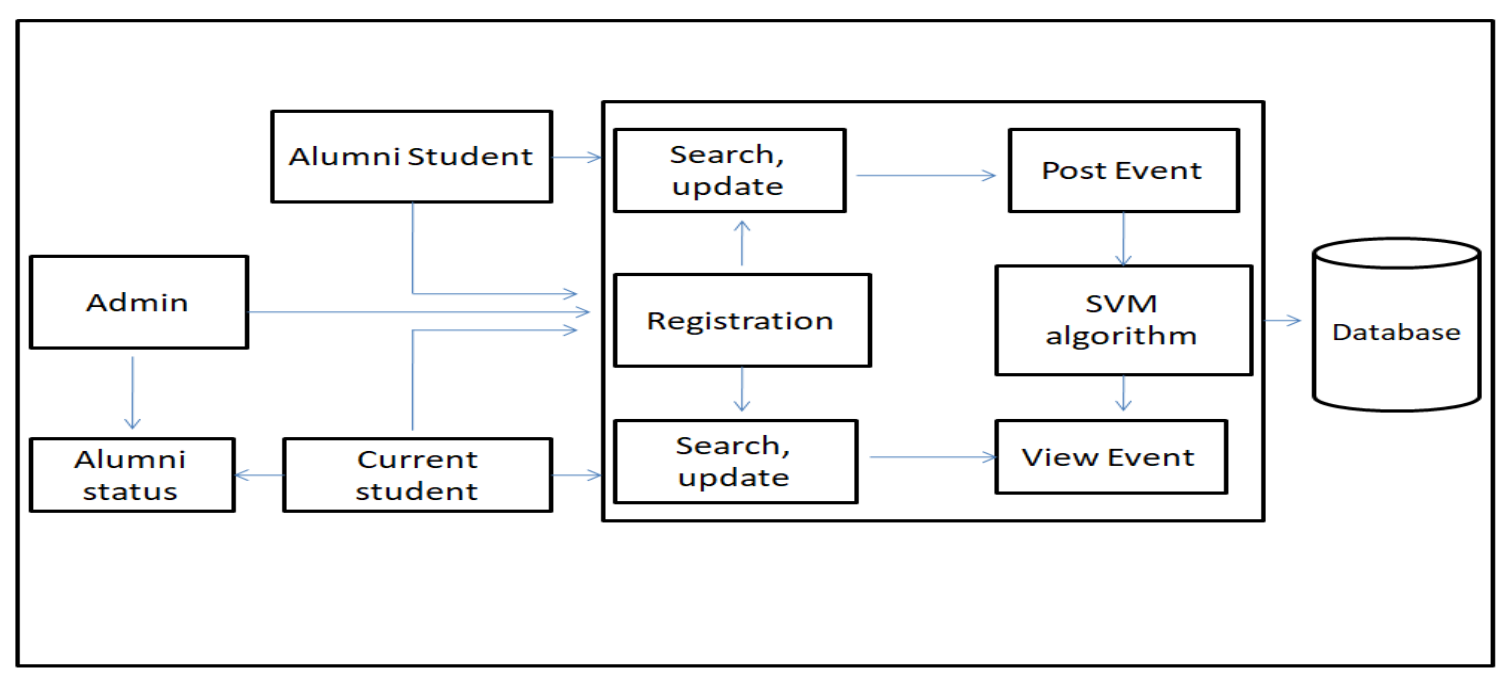

Figure 1. Proposed System Architecture

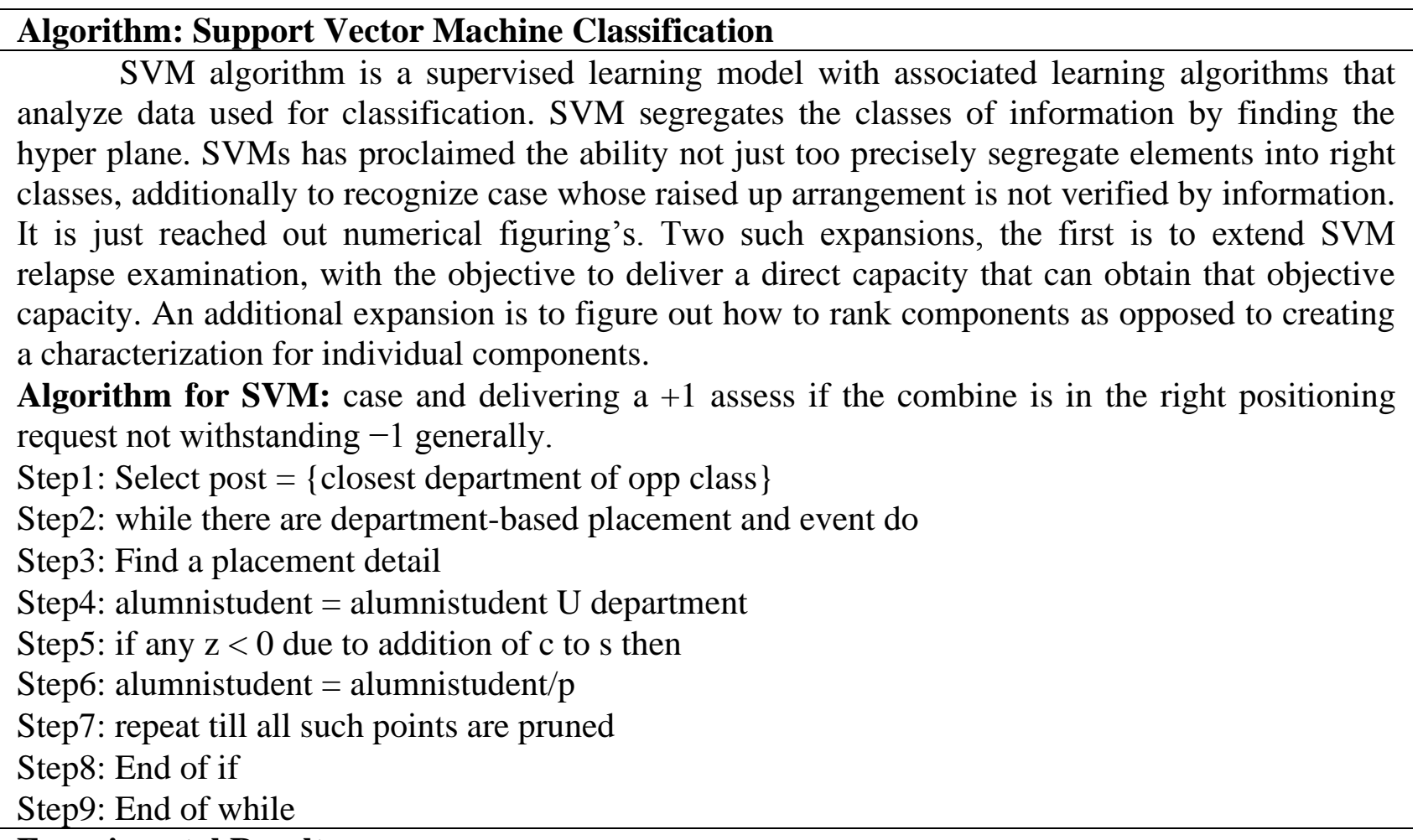

\section{Experimental Results}

The hardware requirement for our proposed system are 4GB RAM, 2.5GHZ Processor, 3.8GB Memory, Windows 10 Pro OS, 466GB Hard disk space, AMD Radeon ${ }^{\mathrm{TM}}$ R4 Graphics and 
1366x768x60hz display. The Software requirements are ASP.net for frontend and SQL server for backend. In this system, we apply the method to classify the placement and event posts to the alumni and the current students during their sight based on their department. Admin can see all departments' related posts which are sent and received by him. Current students search and chat with alumni to have a good future in technical world. Alumni can also search their college mates to increase their circle or to develop in their field. Non-employed alumni can get a good job through the placement's posts in this application. Admin should verify and then activate the alumni. Admin should monitor the system actively and have a proper maintenance over it. Here, we are using support vector machine for classification. When comparing to other classification algorithms it classifies quickly and produce results without dumping of unrelated information.
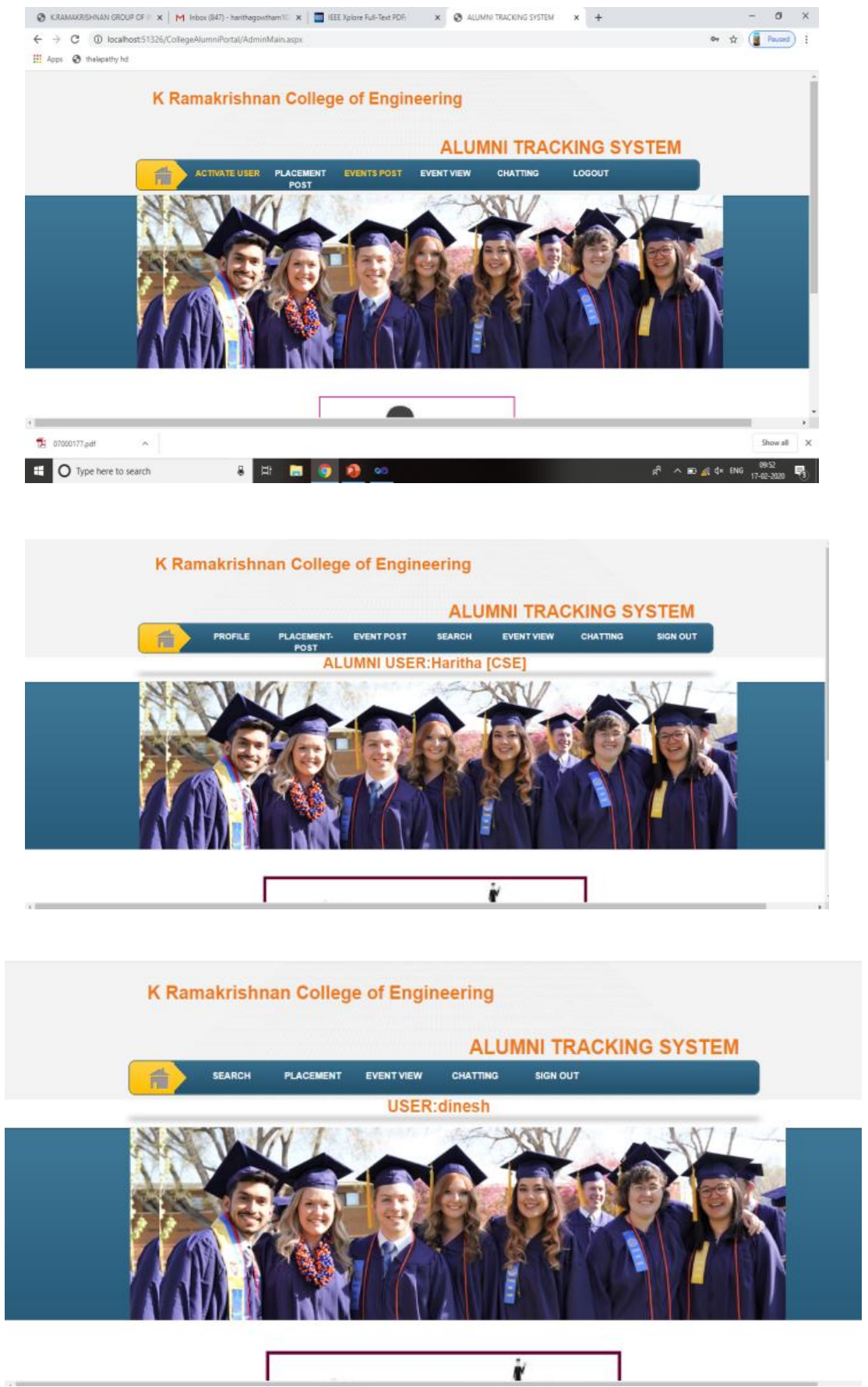
R. Sasikumar et al. / International Research Journal of Multidisciplinary Technovation 2020; 2(5): 42-50

PLACEMENT CELL VIEW
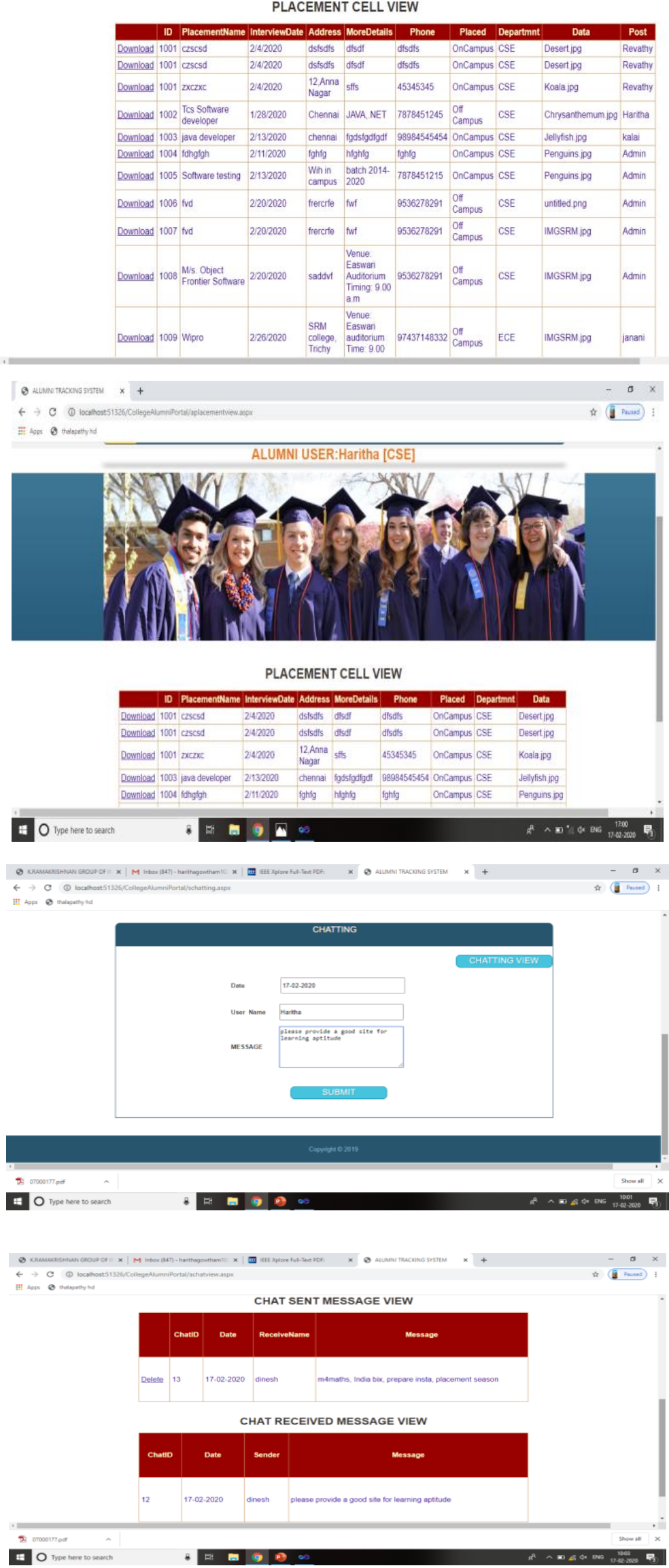


\section{Conclusion}

Alumni portal for any college website is very vital of all alumni. Alumni portal has been setup to increase relations, information sharing and networking among the alumni students. Alumni portal focus on bringing jointly alumni students of college. The primary goal of this report is to attach the alumni students with the college and existing college students with the help of alumni web portal where they can have communication with existing students and college. By using this system, a great interaction can be maintained among alumni and with the college and the students. A good networking can be developed in between the current student and alumni, by using this system the student can clear their doubt in any area, the Alumni student can share their knowledge, materials everything through this application. The department can get any information about alumni easily by using this system, in case of any urgent need.

\section{References}

[1] G. R. Gonçalves, A. A. Ferreira, G. T. de Assis, A. I. Tavares, (2014) Gathering Alumni Information from a Web Social Network, In 2014 9th Latin American Web Congress, IEEE, 100-108.

[2] S. Quarteroni, S. Manandhar, (2007) A Chatbot-based Interactive Question Answering System, Proceedings of the 11th Workshop on the Semantics and Pragmatics of Dialogue, Trento, Italy, 83-90.

3. N. Dahlbäck, A. Jönsson, L. Ahrenberg, (1993) Wizard of Oz studies: why and how, In Proceedings of the 1st international conference on Intelligent user interfaces, 193-200.

[3] M. De Boni, S. Manandhar, Implementing Clarification Dialogues In Open Domain Question Answering, Natural Language Engineering, 11 (2005) 343-362.

[4] D. L. Eisler, Campus Portals: Supportive Mechanisms for University Communication, Collaboration, And Organizational Change, Journal of Computing in Higher Education, 13 (2001) 3-24.

[5] V. Pawar, S. Date, S. Iyer, C. Narvekar, M. Shell, (2002) Security Mechanism In Alumni Portal, Department of Information Technology, Xavier Institute of Engineering, Mahim (W), Mumbai.

[6] R. Divya, A. Thamarai Selvi, Prabha Susy Mathew, N. Keerthika, Alumni Association Portal, International Journal of Applied Engineering Research, 13 (2018) 9387-9390.

[7] S. Subashini, A. Sowndarya, Alumni Interaction System, International Journal of Computer Science Trends and Technology (IJCST), 5 (2017) 306-309.

[8] U. Rio, (2013) Text Messages Categorization of Collaborative Learning Skills in Online Discussion Using Support Vector Machine, In 2013 International Conference on Computer, Control, Informatics and Its Applications (IC3INA), IEEE, 295-300.

[9] T. Onada, H. Murata, S. Yarmada, (2005) Relevance Feedback Document Retrieval Using Support Vector Machine, In Active Mining, Springer, Berlin, Heidelberg, 59-73

[10] J. Camba, R. E. David, A. Betan, A. Lagman, J. D. Caro, (2016) Student Analytics Using Support Vector Machines, In 2016 7th International Conference on Information, Intelligence, Systems \& Applications (IISA), IEEE, 1-6.

[11] Y. Pang, N. Judd, J. O'Brien, M. Ben-Avie, (2017) Predicting Students Graduation Outcomes through Support Vector Machines, In 2017 IEEE Frontiers in Education Conference (FIE), IEEE, 1-8.

[12] S. Tongman, N. Wattanakitrungroj, (2018) Classifying Positive or Negative Text Using Features Based on Opinion Words and Term Frequency - Inverse Document Frequency, In 2018 5th International Conference on Advanced Informatics: Concept Theory and Applications (ICAICTA), IEEE, 159-164. 
[13] S. Saha, A. Sajjanhar, S. Gao, R. Dew, Y. Zhao, (2010) Delivering Categorized News Items Using RSS Feeds and Web Services, In 2010 10th IEEE international conference on computer and information technology, IEEE, 698-702.

[14] P. Chen, T. Wen, (2006) Margin Maximization Model of Text Classification Based on Support Vector Machines, In 2006 International Conference on Machine Learning and Cybernetics, IEEE, 3514-3518.

[15] T. Onoda, H. Murata, S. Yamada, (2006) Support Vector Machines based Active Learning for the Relevance Feedback Document Retrieval, In 2006 IEEE/WIC/ACM International Conference on Web Intelligence and Intelligent Agent Technology Workshops, IEEE, 389-392.

[16] B. Liu, Z. F. Hao, J. Lu, S. Q. Liu, (2007) Apply Support Vector Machine for CRM Problem, In 2007 International Conference on Machine Learning and Cybernetics, IEEE, 3288-3292.

[17] M. Ross, C. A. Graves, J. W. Campbell, J. H. Kim, (2013) Using Support Vector Machines to Classify Student Attentiveness for the Development of Personalized Learning Systems, In 2013 12th International Conference on Machine Learning and Applications, IEEE, 325328.

[18] "Embellishgroup Alumni Management System"[online]. Available: http://alumni.kpdjac.org/.

[19] A. C. Braun, U. Weidner, S. Hinz, (2011) Support Vector Machines, Import Vector Machines and Relevance Vector Machines for Hyperspectral Classification - a Comparison, In $20113 \mathrm{rd}$ Workshop on Hyperspectral Image and Signal Processing: Evolution in Remote Sensing (WHISPERS), IEEE, 1-4.

\section{Acknowledgement Nil}

\section{Funding}

This study was not funded by any grant

\section{Conflict of interest}

None of the authors have any conflicts of interest to declare.

\section{About The License}

The text of this article is licensed under a Creative Commons Attribution 4.0 International License

\section{Cite this Article}

R. Sasikumar, B. Haritha, T. Borshiya Vincy, M. Kamali, Alumni Info-Com Management with Distinct Classification of Data, International Research Journal of Multidisciplinary Technovation, Vol 2, Iss 2 (2020) 42-50.

DOI: https://doi.org/10.34256/irjmt2057 